\title{
Clearance and Early Hydrolysis of Atrial Natriuretic Factor In Vivo Structural Analysis of Cleavage Sites and Design of an Analogue That Inhibits Hormone Cleavage
}

Cindra L. Condra, Elizabeth A. Leidy, Patricia Bunting, Christiane D. Colton, Ruth F. Nutt, Michael Rosenblatt, and John W. Jacobs

Department of Biological Research, Merck Sharp \& Dohme Research Laboratories, West Point, Pennsylvania 19486

\begin{abstract}
This study examines the clearance and early hydrolysis of atrial natriuretic factor (ANF) in vivo. Radiolabeled ANF was cleared from the circulation of the rat with biphasic kinetics; the majority $(90 \%)$ of ANF cleared with a $t_{1 / 2}$ of $15 \mathrm{~s}$, the remaining peptide was cleared with a $t_{1 / 2}$ of 5 min. Microsequence analysis of ANF peptides recovered from the circulation of rats revealed five major degradation products of the intact hormone. The first cleavage occurred between amino acids 12 and 13 of the hormone and would inactivate ANF. Over time, additional fragments of the hormone were generated, including fragments of $6,7,21$, and 24 amino acids in length.

Whole body radioautography of rats injected with [ $\left.{ }^{123} \mathrm{I}\right]-$ ANF revealed the kidney as a predominant organ involved in clearance of ANF. Subsequent amino acid sequence analyses of radiolabeled ANF exposed to the kidney in vivo indicated that this organ generated four of the five major hydrolysis products observed in circulation, namely, the 6, 7, 16, and 21 amino acid fragments of the hormone. In an attempt to stabilize ANF in vivo, a synthetic analogue of the hormone was prepared that contained the amino acid analogue, aminoisobutyric acid, substituted at position 13. This analogue completely abolished the in vivo cleavage of ANF at this site. These studies demonstrate the usefulness of a protein chemistry approach in characterizing hormone metabolism in vivo and designing analogues with enhanced in vivo stability to cleavage.
\end{abstract}

\section{Introduction}

The mammalian heart synthesizes and secretes the 28-amino acid peptide, atrial natriuretic factor (ANF), ${ }^{1}$ which is a potent vasorelaxant, hypotensive, diuretic, and natriuretic hormone

This article was presented in part at the 1987 Second World Congress on Biologically Active Atrial Peptides, NY, and was submitted in abstract form for publication in Biologically Active Atrial Peptides ASH Symposium, vol. II.

Address all correspondence to Dr. John W. Jacobs, Department of Biological Research, Merck Sharp \& Dohme Research Laboratories, West Point, PA 19486.

Received for publication 22 June 1987 and in revised form 30 November 1987.

1. Abbreviations used in this paper: ANF, atrial natriuretic factor; APIII, atriopeptin III (Ser - Tyr $_{28}$ ); hANF, human ANF ( Ser $_{1}-\mathrm{Tyr}_{28}$ ); ${ }^{125}$ I, [3-125I]iodotyrosyl ${ }^{28}$; rAIB 13 (3-28), rat aminoisobutyric acid; rANF, rat ANF ( $\left.\operatorname{Ser}_{1}-\mathrm{Tyr}_{28}\right)$.

\section{J. Clin. Invest.}

(c) The American Society for Clinical Investigation, Inc. 0021-9738/88/05/1348/07 \$2.00

Volume 81, May 1988, 1348-1354
(1-4). After secretion, ANF binds to cell-surface receptors to elicit these physiological responses. Receptors for ANF have been identified in a variety of tissues and vasculatures, including the kidney, adrenal cortex, liver, lung, brain, and eye (5-8). Furthermore, binding and affinity cross-linking studies have shown that vascular cells have multiple and functionally distinct ANF-binding sites (9).

Although there is detailed knowledge concerning the interactions of ANF with its receptor, the exact manner in which ANF is metabolized in vivo after its secretion by the heart remains to be elucidated. Previous investigators have indicated that ANF is rapidly cleared from circulation, with half-life rates of disappearance ranging from 15 to $31 \mathrm{~s}$ in rats $(10,11)$ and 2.5 to $2.95 \mathrm{~min}$ in humans $(12,13)$. In these studies, the disappearance of radiolabeled ANF or of immunoreactive ANF is measured after a bolus injection of ANF peptide(s). The short durations of the biological responses to bolus injections of ANF are consistent with these findings and suggest rapid metabolic clearance or inactivation in vivo. To the best of our knowledge, studies that structurally define the metabolic pathway and structural changes the hormone undergoes during degradation in mammals have not been reported.

To elucidate the nature and possible organ site of ANF degradation, we undertook a protein sequence analysis of ${ }^{125} \mathrm{I}$ ANF that was exposed to the circulation of the rat and dog. We have identified major in vivo proteolytic cleavage sites within the hormone. In addition, we have demonstrated that substantial degradation can take place rapidly in the kidney. Finally, by delineating amino acid sequences within the ANF molecule that are susceptible to cleavage, we have designed an ANF analogue that is resistant to a specific cleavage in vivo. Such studies of the physiological degradation of ANF provide precise knowledge of the proteolytic cleavage sites within the secreted peptide and of the possible organs responsible for metabolism.

\section{Methods}

Radiolabeled peptides, ([3-125I]iodotyrosyl ${ }^{28}$ ). Human ANF (hANF) and $\left(\left[3-{ }^{125} I\right]\right.$ iodotyrosyl $\left.{ }^{28}\right)$ rat ANF (1-28) $\left({ }^{125}\right.$ I-rANF) were obtained from the Amersham Corp. (Arlington Heights, IL) 2,000 Ci/mmol sp act. An aminoisobutyric acid-containing ANF analogue, rAIB13(328), was prepared by C. D. Colton at Merck Sharp \& Dohme Research Laboratories, West Point, PA. The material was iodinated using the chloramine $\mathrm{T}$ and sodium ${ }^{125} \mathrm{I}$ iodide technique employed by the Amersham Corp. to $2,000 \mathrm{Ci} / \mathrm{mmol}$ sp act. ${ }^{123} \mathrm{I}$-labeled rANF (1-28) was prepared using iodogen as the oxidizing agent. Radioiodinated peptides were purified to homogeneity by reverse phase $C_{18}$ HPLC and the placement of the radiolabeled iodine was verified by protein sequence analysis.

Previous work from our and other laboratories $(8,14)$ established that monoiodinated ANF possesses full biological activity in a number of assays, including cyclic guanosine monophosphate generation in cultured vascular cells and relaxation of aortic rings. There is, however, 
a slight loss in potency of ANF when a single iodine is added to the $\mathrm{COOH}$-terminal tyrosine residue.

Biodistribution of ${ }^{123} I-A N F$. A Technicare 420 gamma camera calibrated for ${ }^{123} \mathrm{I}(159 \mathrm{keV})$ with a high resolution collimator interfaced to a Microdelta computer (Siemens-Allis Inc., Cherry Hill, NJ) was used to image anesthetized (ketamine) male Sprague-Dawley rats. Sequential static images (posterior view) were acquired after the administration of $20-60 \mu \mathrm{Ci}$ of ${ }^{123} \mathrm{I}-\mathrm{ANF}$ via a tail vein catheter. The images were acquired in $128 \times 128$ word matrix for $\sim 8$ min each.

Blood collection. Blood samples for the in vivo studies were either drawn into syringes already containing anticoagulant $(0.7 \mathrm{mg} / \mathrm{ml}$ $\mathrm{Na}_{2}$ EDTA, Fisher Scientific Co., Allied Corp., Pittsburgh, PA); 11.11 $\mathrm{mg} / \mathrm{ml}$ soybean trypsin inhibitor, Boehringer Mannheim Diagnostics, Inc., Indianapolis, IN; 0.5 trypsin inhibitor U/ml aprotinin, Sigma Chemical Co., St. Louis, MO) or were placed immediately into prechilled tubes containing the anticoagulant. Rapid microcentrifugation for $10 \mathrm{~min}$ at $4^{\circ} \mathrm{C}$ pelleted the cellular material. The plasma was carefully removed by pipette to a prechilled tube. One part plasma was mixed with three parts $4 \%$ acetic acid and kept on ice until Sep-Pak extraction

Blood samples for the in vitro studies were collected into syringes containing the appropriate anticoagulant. Serum was obtained by allowing blood (collected without anticoagulant) to form a natural clot overnight at $4^{\circ} \mathrm{C}$. Heparin was obtained from Gibco Laboratories (Grand Island, NY).

Plasma extraction. Disposable syringes were placed on $\mathrm{C}_{18}$ Sep-Pak cartridges (Waters Associates, Millipore Corp., Milford, MA), which were activated by the passage of $10 \mathrm{ml}$ methanol (Fisher Scientific Co., Allied Corp.) and washed with $10 \mathrm{ml}$ distilled water. The acidified samples were passed through the Sep-Pak and the cartridges were washed with $10 \mathrm{ml}$ distilled water followed by $10 \mathrm{ml}$ of $4 \%$ acetic acid. Samples were eluted with $2 \mathrm{ml} \mathrm{86 \%} \mathrm{ETOH-4 \%} \mathrm{acetic} \mathrm{acid.} \mathrm{The} \mathrm{effluent}$ was collected, evaporated to dryness in a Speed-Vac concentrator, and stored at $4^{\circ} \mathrm{C}$ until sequencing. The efficiency of extraction was $\sim 80 \%$ for ${ }^{125} \mathrm{I}$-ANF (1-28).

Protein sequencing. Automated Edman degradation (15) was performed on a protein sequencer (470A; Applied Biosystems, Inc., Foster City, CA) using the sequencing program (tape 400355) supplied with the instrument. The samples were applied to a polybrene-containing glass fiber disk. All cycles were dried before radioactive counting that used an automatic gamma counter (Wallac Clinigamma 1272; LKB Instruments, Inc., Gaithersburg, MD).

Cleavage of $A N F$ in vitro. $0.6 \mu \mathrm{Ci}$ of ${ }^{125} \mathrm{I}$-rANF (1-28) was added to plasma or serum $(400 \mu \mathrm{l})$. Samples were mixed and incubated in a $37^{\circ} \mathrm{C}$ water bath for $4 \mathrm{~min}$. The material was immediately extracted by the Sep-Pak protocol. Similarly, $0.3 \mu \mathrm{Ci}$ of ${ }^{125} \mathrm{I}$-rANF $(1-28)$ was added to blood samples $(200 \mu \mathrm{l})$ collected with and without anticoagulant $(40$ $\mathrm{U}$ heparin/ml blood or $1.6 \mathrm{mg} \mathrm{Na} 2 \mathrm{EDTA} / \mathrm{ml}$ blood), followed by mixing and incubation for $4 \mathrm{~min}$ at $37^{\circ} \mathrm{C}$. These samples were subjected to microcentrifugation at $4^{\circ} \mathrm{C}$ for $10 \mathrm{~min}$ were Sep-Pak extracted, and sequenced.

Cleavage of $A N F$ in vivo. Adult male Sprague-Dawley rats were anesthetized with phenobarbitol. Tail veins were cannulated to allow injection of $25-100 \mu \mathrm{Ci}$ of ${ }^{125}$ I-rANF $(1-28)$ or $100 \mu \mathrm{Ci}$ of ${ }^{125}$ I-rAIB 13 (3-28). A rinse with $1.0 \mathrm{ml}$ saline followed immediately. In rats where samples were prepared for sequence analysis ( ${ }^{125}$ I-labeled peptides), the abdominal cavities were exposed and the blood samples were withdrawn from the aorta. Small volumes were measured for radioactivity directly and larger samples were extracted via the Sep-Pak protocol for subsequent sequence analysis of the radiolabeled ANF peptides.

In experiments in which ANF was directly injected into the renal artery, a mature female beagle was anesthetized with pentobarbitol and $1 \%$ vol expanded with saline. Urine samples were collected over 1-min intervals via a catheter placed in the ureter of the left kidney. Injection of $100 \mu \mathrm{Ci}{ }^{125} \mathrm{I}$-rANF dissolved in saline into the cannulated renal artery of the left kidney was followed by a 1.0-ml saline rinse. Blood samples were removed via the catheterized renal vein. Radioactivity, which was present in small volumes of blood, was determined directly.
Larger volumes of blood were Sep-Pak extracted for sequence analysis. Urine volume and radioactivity in the urine was also determined.

\section{Results}

The structure of ANF is shown in Fig. 1. It is a 28-amino acid peptide with a single disulfide bridge connecting cysteine residues 7 and 23. We initiated our studies by examining the clearance of radiolabeled ANF from the circulation. Fig. 2 shows the time course for the disappearance of ${ }^{125}$ I-rANF after bolus injection into the tail vein of the rat. The disappearance of radioactivity from the bloodstream showed a biphasic curve with a $t_{1 / 2}$ of $15 \mathrm{~s}$ for the initial phase of clearance, where $\sim 90 \%$ of the radiolabeled ANF was removed. The remaining radioactivity showed slower disappearance with a $t_{1 / 2}$ of $5 \mathrm{~min}$.

To examine the metabolic cleavage of the radiolabeled ANF that escapes rapid clearance in circulation, ${ }^{125} \mathrm{I}-\mathrm{rANF}$ (1-28) was injected into the tail vein of rats and blood was sampled at various time points. Edman sequence analyses indicated a time course for the generation of metabolic cleavage fragments of radiolabeled ANF in circulation. As shown in Fig. 3, these studies revealed several preferred cleavage sites in the hormone. The earliest sampling period that was technically feasible (45 s) revealed the appearance of a product corresponding to the 16-amino acid fragment, $\operatorname{Asp}_{13}-\mathrm{Tyr}_{28}$ (Fig. 1). The amounts of this fragment relative to those of intact ANF increased over time (Fig. 3). It should be stressed, as noted above, that the cleavage of intact ANF, which we are examining in these studies, represents that portion of the injected radiolabeled ANF $(\sim 10 \%)$ that has escaped the rapid, initial clearance phase. Subsequent to this initial cleavage event, other peptide fragments are generated (Fig. 3), including fragments of 6-amino acids $\left(\mathrm{Cys}_{23}-\mathrm{Tyr}_{28}\right)$, 7-amino acids (Gly $2 \mathbf{H}^{-}$ $\mathrm{Tyr}_{28}$ ), 21 -amino acids $\left(\mathrm{Phe}_{8}-\mathrm{Tyr}_{28}\right)$, and 24-amino acids $\left(\mathrm{Ser}_{5}-\mathrm{Tyr}_{28}\right)$. In addition, significant levels of ${ }^{125} \mathrm{I}^{-\mathrm{Tyr}_{28}}$ were seen by $4 \mathrm{~min}$ (see cycle 1, $4 \mathrm{~min}$ sample, Fig. 3 ). It should be noted that each time point represented in Fig. 3 represents a separate rat. Two additional time points of 5 and $10 \mathrm{~min}$ were also sampled in these experiments (data not shown). In these later time periods no new ANF-related fragments appeared and there was a substantial reduction in recoverable ANF peptides which indicates a clearance of the metabolic breakdown products of intact ANF. In three separate studies identical sized cleavage products of ANF were observed by microse-

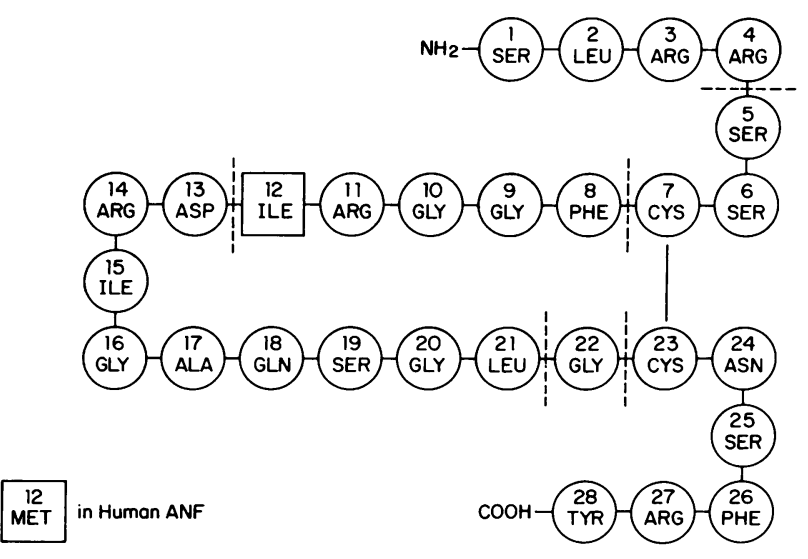

Figure 1. Amino acid sequence of ANF. The dotted lines indicate major in vivo cleavage sites determined in the present study. 


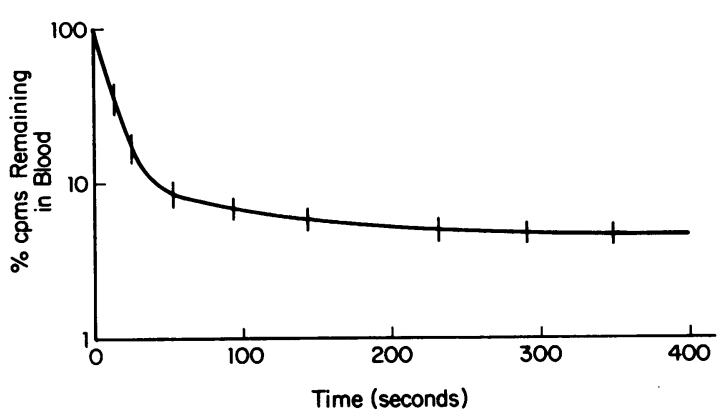

Figure 2. Clearance of ${ }^{125}$ I-rANF (1-28) from circulation. Blood samples were removed at various time intervals after injection of ANF into the tail vein. Direct counts were corrected for total animal blood volume. Data plotted as percentage of total counts per minute injected that remained in circulation.

quence analysis at each respective time point. In addition, the appearance of each fragment followed the same time course as displayed in Fig. 3, with the 16-amino acid fragments, Asp $_{13}-$ $\mathrm{Tyr}_{28}$ always appearing first. As a control, amino acid sequence analyses of ${ }^{125} \mathrm{I}$-ANF before in vivo administration demonstrated a homogeneous radioligand with no fragments present (see panel 1, Fig. 3). A total of 24 independent sequencer runs were used to establish the five cleavage products of ANF that are generated in vivo.

As shown in Fig. 4, no cleavage products of intact radiolabeled ANF were generated after incubation of the hormone for $4 \mathrm{~min}$ in either plasma or serum. Incubation of ANF in whole blood for $4 \mathrm{~min}$, however, resulted in degradation of the 28amino acid peptide to the 24-amino acid peptide termed atriopeptin III (Sers-Tyr 28 ) (APIII). This cleavage was substantially inhibited by EDTA, but was not inhibited by heparin (see Fig. 5).

Since only one of the five cleavages of intact ANF that occur in vivo could be accounted for by proteolysis in circulation, studies were undertaken to identify organs that are involved in the uptake of radiolabeled ANF from the circulation or that mediate hormonal cleavage. rANF (1-28) was labeled with ${ }^{123}$ iodine, an isotope suitable for whole animal autoradi- ography, and injected into the tail vein of the rat. As shown in Fig. 6, gamma camera autoradiography indicated rapid uptake of radioactivity by the kidney with radioactivity persisting in that organ over the course of the studies $(20 \mathrm{~min})$. At later time points (12 and $20 \mathrm{~min}$ ) radioactivity could be seen localized in the thyroid and bladder. A relatively small amount of radioactivity was concentrated in the area of the liver. It should be stressed that these studies only follow distribution of radioactivity in the animal; caution should be exercised in extrapolating from these studies to sites of ANF clearance which are physiologically relevant. Nevertheless, such studies do indicate potential sites of in vivo clearance and degradation of ANF which can then be systematically explored.

To examine whether any of the degradation products identified could be generated by the kidney, we performed in vivo experiments in which radiolabeled ANF was injected directly into the renal artery, followed by rapid sampling of the renal venous effluent. We chose to use dogs for these studies as larger blood samples could be obtained and rapid sampling of venous effluent was more technically feasible than in the rat. Blood samples were processed in a manner similar to that previously described. Each time point represents a separate dog and a total of three dogs were used in the study. As depicted in Fig. 7, by $15 \mathrm{~s}$ degradation products of intact ANF (which were of 6, 7, and 21 amino acids long) were observed. A small amount of the 16-amino acid fragment was also present. A small amount of a 19-amino acid fragment was also present at the 15-s time point, however, this finding was not reproducible. The 24-amino acid peptide, APII, was not detected at either time point. Thus, the kidney can generate four out of the five cleavage products of intact ANF that has escaped the rapid, initial clearance phase.

Blood pressure and heart rate of the dog did not increase during this experiment. Renal blood flow increased $15 \%$ and urine volume rapidly increased $600 \%$, indicating that there is a biological response to $\sim 200 \mathrm{ng}$ of radiolabeled ANF injected into the renal artery. Within $20 \mathrm{~min}$, urine volume returned to initial levels. Radioactivity in the urine increased rapidly after injection of ${ }^{125} \mathrm{I}$-ANF, but attempts to extract radiolabeled ANF from urine failed. None of the radioactivity in the urine was retained on Sep-Pak $C_{18}$ column, which was consistent
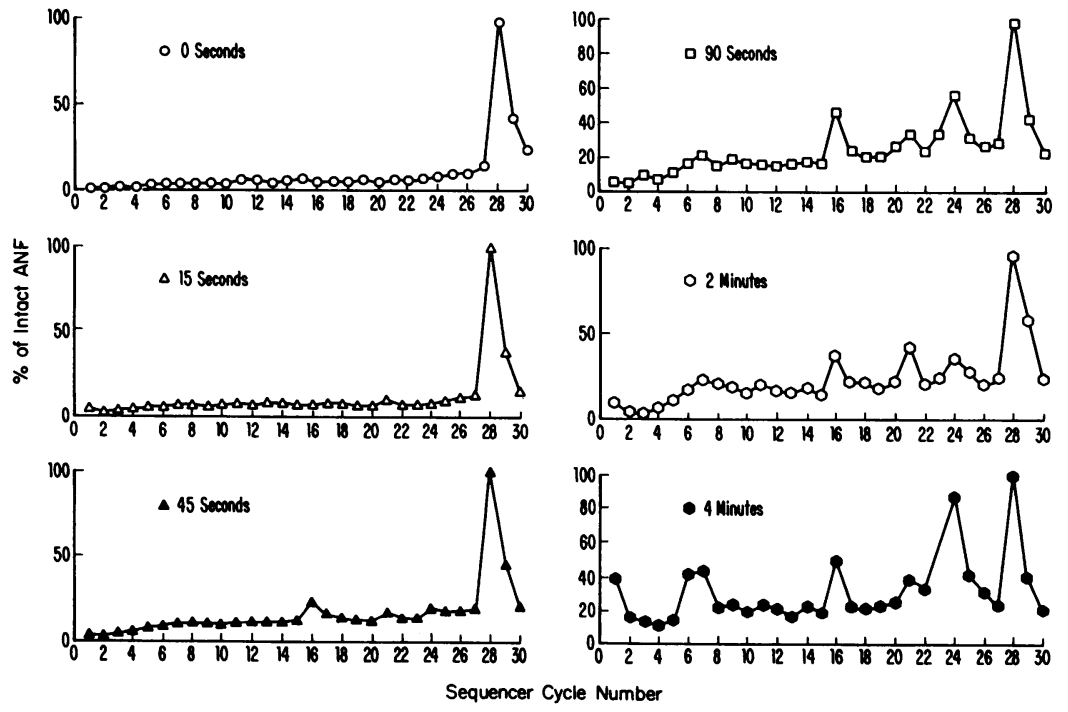

Figure 3. Early hydrolysis of ${ }^{125}$ I-rANF $(1-28)$ in rats. Radiolabeled ANF was injected into the tail veins of rats, blood samples were removed, processed by SepPak extraction, and subjected to amino acid sequence analyses. The caption on the $y$ axis, "\% of intact ANF," refers to the portion of ANF (10\% of total) that escaped the initial, rapid clearance phase. 


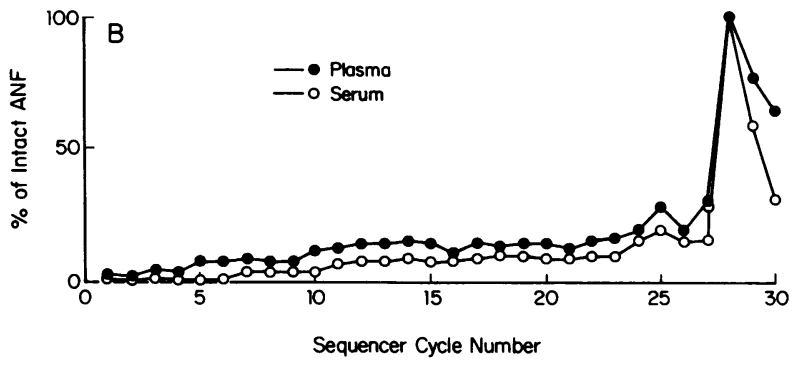

Figure 4. Metabolism of ${ }^{125} \mathrm{I}$-rANF in plasma or serum. ${ }^{125} \mathrm{I}$-rANF $(1-28 ; 0.6 \mu \mathrm{Ci})$ was incubated in $400 \mu \mathrm{l}$ plasma or serum for $4 \mathrm{~min}$ at $37^{\circ} \mathrm{C}$. After Sep-Pak extraction and sequencing, the radioactivity recovered in each cycle was plotted as a percentage of radioactivity recovered in cycle 28 (intact ANF).

with degradation of ANF to relatively small peptides or amino acids and liberation of free label. In an independent experiment, intact ${ }^{125}$ I-hANF (1-28) added to urine was extracted by the Sep-Pak protocol with an efficiency of $85 \%$.

We next turned our attention to the possibility that specific cleavages of the ANF molecule in vivo could be blocked by appropriately designed analogues. In our rat experiments (Fig. 3) the 16-amino acid peptide, $\mathrm{Asp}_{13}-\mathrm{Tyr}_{28}$, was the first metabolic breakdown product of ANF observed in that fraction of ANF that escaped the initial, rapid clearance phase. This fragment results from cleavage of ANF between the aspartic acid residue at position 13 and isoleucine at position 12 (Fig. 1). In an attempt to block cleavage at this site in vivo, a 26-amino acid ANF analogue ( $\left.\mathrm{Arg}_{3}-\mathrm{Tyr}_{28}\right)$, which contained a substitution at position 13 (the nonnatural amino acid, AIB), was chemically synthesized. This ANF analogue was then radiolabeled at the tyrosine residue located at position 28 and injected into the rat. We saw no detectable change in the metabolic clearance rate of this analogue when compared with native ANF (see Fig. 2 and text). However, as seen in Fig. 8, this modification at residue 13 eliminated all detectable cleavage of the ANF analogue between positions 12 and 13. The 6- and 7-amino acid peptide fragments observed previously (Fig. 3) were still generated, which provided evidence for the specificity of protection from enzymatic degradation that is afforded by the substitution in the analogue. A total of four sequence

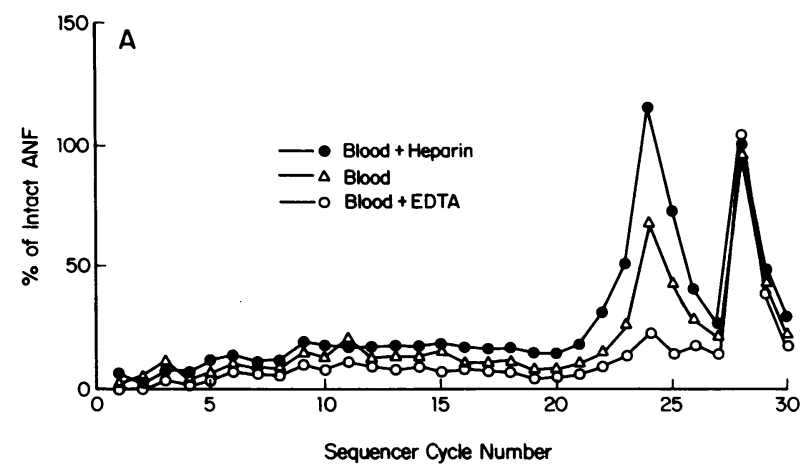

Figure 5. Metabolism of ${ }^{125} \mathrm{I}$-rANF in blood. ${ }^{125} \mathrm{I}$-rANF $(0.3 \mu \mathrm{CI})$ was incubated in $200 \mu \mathrm{l}$ of either whole blood with no anticoagulant, whole blood with $40 \mathrm{U}$ heparin/1.0 ml, or whole blood with $1.6-\mathrm{mg}$ $\mathrm{Na}_{2} /$ EDTA/1.0 ml for $4 \mathrm{~min}$ at $37^{\circ} \mathrm{C}$. Sep-Pak extraction and sequencing were performed as described in Methods.
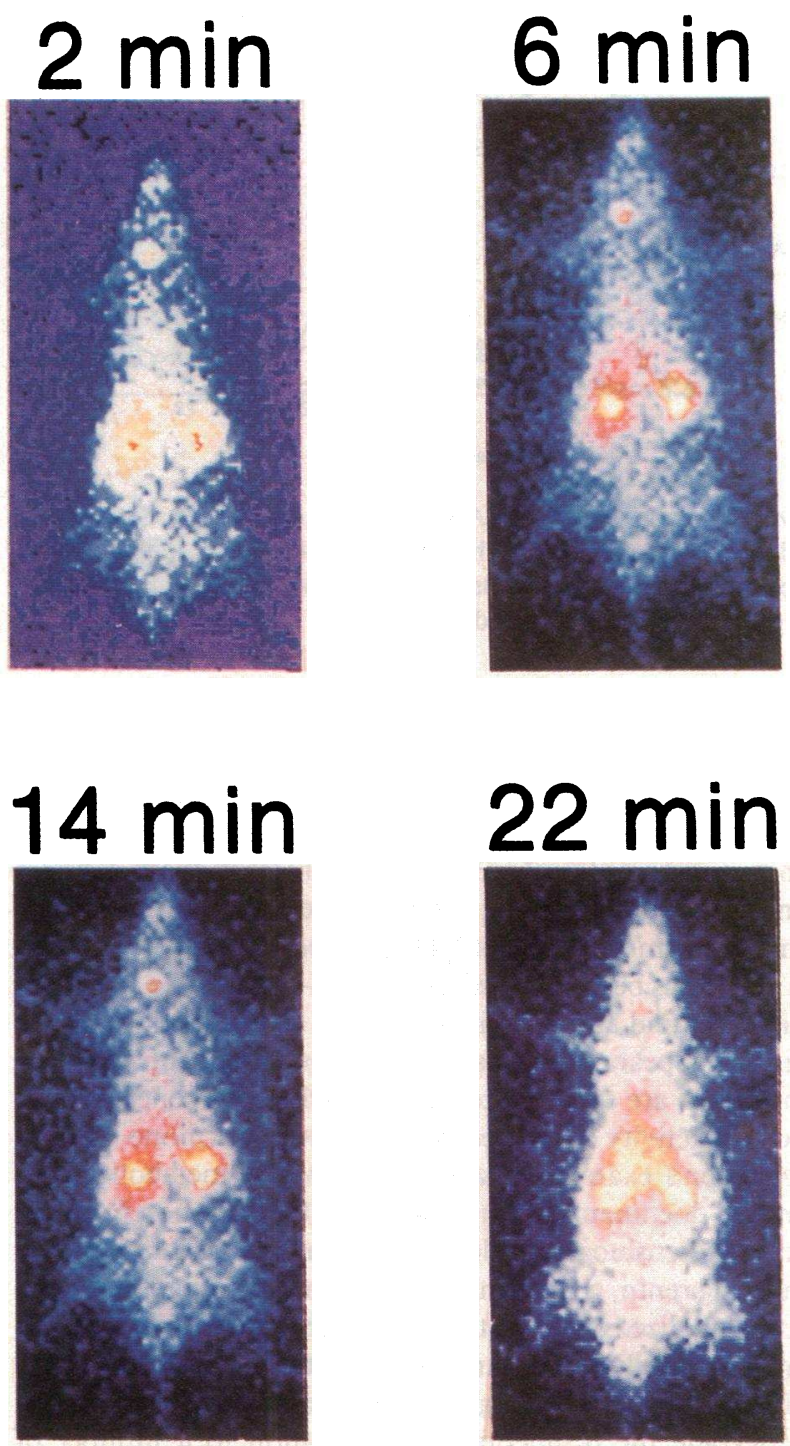

Figure 6. Gamma camera autoradiography of a rat injected with $\mathbf{4 0}$ $\mu \mathrm{Ci}$ i.v. of ${ }^{123} \mathrm{I}$-ANF. Details are provided in the Methods section.

analyses in two separate animals were performed, with quantitatively similar results obtained in each study. In no case was any cleavage seen at position 13 .

The amounts of the 21- and 24-amino acid degradation products were diminished in these experiments (compare Fig. 8 with Fig. 3), which was most likely due to the difficulty of sequencing through the AIB residue at position 13 and not to altered metabolism of the analogue at these cleavage positions. When the intact radiolabeled analogue containing AIB at position 13 was subjected to automated Edman degradation (inset, Fig. 8), all radioactivity should have been released at cycle 26. However, a significant amount of radioactivity was not released until cycles 27 and 28 . This suggests that there was a substantial amount of "overlap" generated in the Edman degradation procedure which may have been caused either by earlier incomplete coupling or by cleavage of the AIB residue at position 13. What is clear, despite this technical issue, is that this modification completely abolished the in vivo metabolism of ANF at this cleavage site. 


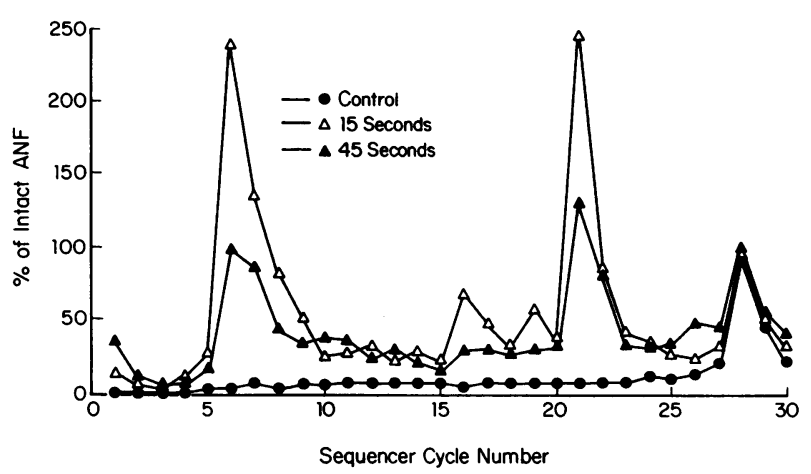

Figure 7. Metabolism of ${ }^{125}$ I-rANF (1-28) in dog kidney. Radiolabeled ANF was injected into the renal artery of the left kidney. Blood samples were taken at intervals from the renal vein via catheter and syringe as described in Methods.

\section{Discussion}

Although there is a great deal of information on the chemistry and pharmacology of ANF $(6,16,17)$, the metabolism of this hormone remains largely unexplored. This is in sharp contrast to information concerning other polypeptide hormones. For example, the metabolism of PTH has been extensively studied (15) and it has been revealed that the 84-amino acid hormone undergoes rapid and specific proteolysis after secretion, resulting in the appearance of discrete hormone fragments in circulation which are expected to have a marked difference in their biological activity compared with the intact hormone (15).

A second example of a hormone whose metabolism has been well documented is angiotensin. After secretion from the liver, angiotensinogen is cleaved at a single Leu-Leu bond by circulating renin, generating angiotensin I. This peptide is further metabolized by angiotensin converting enzyme, which is located primarily in the lung, to the potent peptide hormone, angiotensin II. Specific angiotensin II degrading enzymes rapidly degrade the octapeptide in circulation to a number of smaller, biologically inactive peptides.

In the present studies, we have sought to define the structural pathway for ANF metabolism in vivo. To accomplish this, we have used a sensitive microsequencing procedure first applied to the study of the metabolism of PTH in vivo (15). Following this approach, hormone is radiolabeled to a high

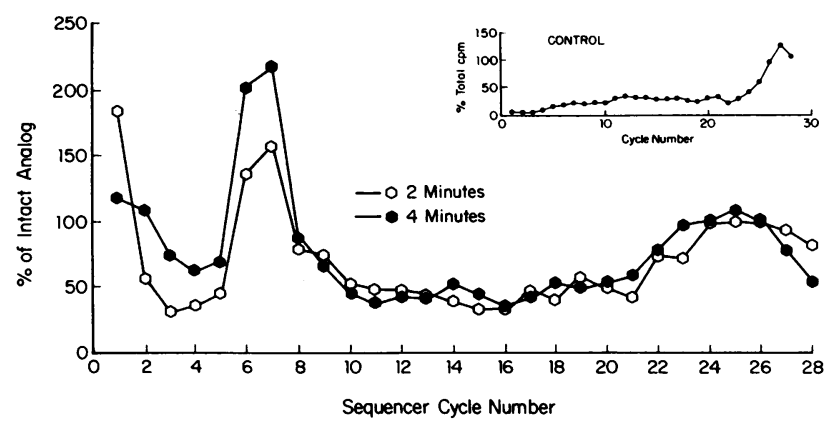

Figure 8. Metabolism of ${ }^{125}$ I-rAIB13 (3-28) in rats. The radiolabeled ANF analogue that contained aminoisobutyric acid was injected into the tail veins of rats, and blood samples were withdrawn from the aortas. Extraction as described in Methods. (Inset) Sequence analysis of ${ }^{125}$ I-rAIB 13 before injection into the rat as a control. specific activity and then injected into the circulation of an animal. Subsequently, sequence analysis of blood samples containing the radiolabeled hormone and its metabolites is performed. An important feature of this method is that precise cleavage points in the sequence of the hormone in vivo are readily deduced from the number of cycles of Edman degradation required to identify radioiodotyrosyl at position 28 . A second advantage is that there is no need to separate intact hormone from hormone fragments of closely similar molecular weights; the sequence analysis approach readily distinguishes these peptides chemically, even though they may differ by as little as a single amino acid. The precision of this characterization is in contrast to characterization that is obtained when hormone metabolism is examined in vivo using an immunological approach. Antibodies raised to intact hormone may or may not cross-react (often to differing extents) with the degradation products that are generated, thus complicating quantitative comparisons. A third advantage of the sequence analysis approach is that by using radiolabeled ANF of high specific activity, only small quantities of the tracer need be injected, allowing analysis of ANF metabolism at concentrations of the hormone close to those found physiologically.

Obviously, for the microsequencing approach to be valid, the radiolabeled tracer that is used must be biologically active, homogeneous, labeled at a single position, and free of any contaminating hormone fragments before administration to the animals. To address these issues, the radiolabeled ANF used in this study was subjected to sequence analysis and demonstrated to be homogeneous and devoid of smaller radiolabeled fragments (see Figs. 3 and 6). The radioligand has been evaluated in two bioassays: $(a)$ cell-surface receptor binding assays in target tissues, including membranes from rabbit aorta (Condra, C., and R. Nutt, unpublished observations) and cultured bovine endothelial cells (18). Dissociation constants determined by receptor binding assays with the radioligand were in close agreement with the anticipated biological potency of ANF in whole artery relaxation assays (8); and $(b)$ direct measurement of diuresis, heart rate, blood pressure, and renal blood flow when radiolabeled ANF was injected into the renal artery (Fig. 6).

A number of investigators using other techniques have examined the clearance rate, site, and products of degradation of ANF. Due to differences in experimental design, it is often difficult to directly compare these studies. There are differences in the amount of exogenous ANF intravenously administered, and the clearance and degradation pathways for near physiological concentrations of ANF may differ in rate or pattern of metabolites generated from those used when larger doses of the hormone are administered. Furthermore, the method (infusion vs. bolus injection) and location of administration or sampling can influence the apparent clearance rate of ANF and the type of degradation product(s) recovered. Also, the peptide fragment used in metabolism studies and the techniques used to detect the products of degradation vary. For example, studies have been performed using ANF ( Ser $_{1}$ $\left.\mathrm{Tyr}_{28}\right)$, ANF $\left(\mathrm{Arg}_{3}-\mathrm{Tyr}_{28}\right)$, and ANF $\left(\mathrm{Ser}_{5}-\mathrm{Tyr}_{28}\right)$. Estimates of the hormone clearance have been based on measurements of ANF immunoreactivity, ANF biological activity, and recovery of the radioactive hormone. Such differing techniques might be expected to yield dissimilar clearance rates. Murthy et al. (14) followed the disappearance of radiolabeled ANF from rat circulation and demonstrated rapid clearance of the peptide 
with a $t_{1 / 2}$ of $17 \mathrm{~s}$ in one study and $t_{1 / 2}$ approaching $1 \mathrm{~min}$ in another study (19). DeVine et al. (10) obtained an initial $t_{1 / 2}$ of $15 \mathrm{~s}$ for the clearance of radiolabeled APIII in rats with a longer second phase of 7-10 min. Katsube et al. (11) reported the half-life of exogenous APIII to be $31 \mathrm{~s}$ in normal rats and $64 \mathrm{~s}$ in nephrectomized animals. The $t_{1 / 2}$ value we obtained for the clearance of ANF from the circulation of normal rats agrees with these studies. One disparity between the findings of the present study and those noted above concerns our findings that the kidney can metabolize intact ANF. From our studies, we conclude that the kidney is capable of producing four of the five rapidly generated ANF metabolic breakdown products detected in vivo. Whether the kidney, in fact, is the organ that produces these cleavages in the intact animal is, at present, unknown. It should be noted that other investigators have implicated the involvement of the kidney in ANF metabolism by the demonstration of specific membrane receptors in renal tissues (8), the radioautographic localization of ${ }^{125} \mathrm{I}-\mathrm{ANF}$ in renal tissues (5), and the removal of immunoreactive ANF by passage through the kidney $(20,21)$. Hepatic clearance of ANF has recently been demonstrated in human subjects, indicating that this organ also contributes to clearance of ANF (22).

In another study relevant to the present work, Veress et al. (23) demonstrated that incubation of intact ANF with whole blood reduced the natriuretic activity of this hormone. Specifically, it was shown that a white cell/platelet fraction of whole blood was involved in the metabolism. Other studies confirmed the presence of platelet binding sites for $\operatorname{ANF}(24,25)$. The findings from the present studies are compatible with these earlier results. Our experiments indicate the manner in which a metabolic breakdown product of ANF, APIII, is generated in vivo: APIII is generated rapidly in circulation and not through metabolism in the kidneys or vascular receptors. It should be noted that APIII is biologically active as a vasorelaxing, natriuretic, and diuretic agent (26).

In the present studies amino acid sequence analyses were employed to precisely define cleavage sites that occurred within the ANF molecule after in vivo administration. It should be stressed that the majority of ANF clearance most likely involves a nonenzymatic pathway; metabolites of ANF appear in circulation after the majority (90\%; Fig. 2) of the hormone is cleared. The cleavage of ANF at specific amino acid residues in vivo occurs in a time-dependent fashion (Fig. 3). The earliest detectable cleavage occurred at $45 \mathrm{~s}$ in the rat between residues 12 and 13 (Ile-Asp) and would inactivate the hormone $(16,26,27)$. This was followed by cleavages between residues 4 and 5 (Arg-Ser) and residues 7 and 8 (Cys-Phe), which were first prominent at $90 \mathrm{~s}$. By 4 min, additional fragments were observed resulting from proteolysis between residues 22 and 23 (Gly-Cys) and residues 21 and 22 (Leu-Gly). The cleavage sites in ANF (the fraction of ANF that has escaped the initial clearance phase) are summarized in Fig. 1. The kidney is capable of performing all these cleavages except the one between residues 4 and 5 (Figs. 1 and 6). This proteolysis occurs in a blood fraction (Fig. 5). The amino acid sequences at the cleavage sites are of interest. The only trypticlike cleavage is after the arginine residue at position 4 , a cleavage that occurs in the blood and which does not inactivate ANF. Recently, Stephenson and Kenny (28) demonstrated hydrolysis of hANF (1-28) by purified endopeptidase-24.11 (EC 3.4.24.11) and by pig kidney microvillar membranes. Although no sequence data on ANF metabolites was reported,
HPLC analysis of ANF-related fragments indicated that one site of hydrolysis was between residues 7 and 8 (Cys-Phe) of ANF, a cleavage we also observed (Fig. 3).

The identification of sites of proteolysis within ANF permitted the subsequent design of an ANF analogue that would afford resistance to this cleavage. The analogue, which contains substitution of an AIB residue at position 13, was completely resistant to cleavage at this position over the time course studied. Systematic replacement of noncleavable amino acid residues at other labile positions within the ANF molecule may permit the generation of an ANF analogue that is completely stable with respect to enzymatic cleavage in vivo. It is possible, however, that such modifications may increase the stability of ANF in vivo without enhancing bioactivity. In this regard, the AIB-containing analogue showed reduced biological potency. In receptor binding assays, this analogue displayed only $3 \%$ of the potency of native hormone and in whole vessel relaxation assays was only $9 \%$ as potent as native ANF (Condra, C., and R. Winquist, unpublished observations). Given the critical role for biological activity of residues within the disulfide-bonded ring structure of ANF (residues 7-23), it is not surprising that modifications within this region may reduce bioactivity. In preliminary experiments we have also shown that the AIB-containing analogue is cleared as rapidly by the nonhydrolytic pathway as native ANF in the rat. Therefore, we would predict that this analogue would not show increased duration of action in vivo.

The design of ANF analogues that offer some advantage over the native hormone is a complex problem. Multiple approaches will have to be used to critically define amino acid modifications that alter biological activity as well as modifications that attenuate rapid clearance of the peptide. Such information, when combined with knowledge concerning modifications that block metabolism of hormone, offers promise for the ultimate design of longer acting compounds suitable for therapy of hypertension or edema. As structure/function studies better define the nature of ANF-receptor interactions and as the precise contributions of certain organs to the metabolic degradation of ANF are described, it may be possible to design analogue that retain biological potency, but that resist in vivo cleavage.

\section{Acknowledgments}

We thank Drs. Howard Solomon, Larry Spitznagle, Chris Fioravanti, and George Tyler for assistance with the ${ }^{123} \mathrm{I}$-ANF studies, and Drs. Dan Veber, Ray Winquist, and Paul Friedman for suggestions concerning these studies. We thank Carole Hannan for secretarial assistance.

\section{References}

1. Sylvestre, D. J., J. B. Zisfein, R. M. Graham, and C. J. Homcy. 1986. Serum-mediated enhancement of ANF accumulation in the culture medium of cardiac atriocytes. Biochem. Biophys. Res. Commun. 140:151-159.

2. Anderson, J. V., and S. R. Bloom. 1986. Atrial natriuretic peptide: what is the excitement all about? J. Endocrinol. 110:7-17.

3. Thibault, G., R. Garcia, J. Gutowska, C. Lazure, N. G. Seidah, J. Chretien, J. Genest, and M. Cantin. 1986. Identification of the released form of atrial natriuretic factor by the perfused rat heart. Proc. Soc. Exp. Biol. Med. 182:137-141.

4. Flynn, T. G., M. L. de Bold, and A. J. de Bold. 1983. The amino 
acid sequence of an atrial peptide with potent diuretic and natriuretic properties. Biochem. Biophys. Res. Commun. 117:859-865.

5. Bianchi, C., J. Gutkowska, G. Thibault, R. Garcia, J. Genest, and M. Cantin. 1985. Radioautographic localization of ${ }^{125} \mathrm{I}$-atrial natriuretic factor (ANF) in rat tissues. Histochemistry. 82:441-452.

6. Thibault, G., R. Garcia, J. Gutkowska, J. Genest, and M. Cantin. 1986. Atrial natriuretic factor: a newly discovered hormone with significant clinical implications. Drugs. 31:369-375.

7. Bianchi, C., M. B. Anand-Srivastava, A. De Lean, J. Gutkowska, D. Forthomme, J. Genest, and M. Cantin. 1986. Localization and characterization of specific receptors for atrial natriuretic factor in the ciliary processes of the eye. Curr. Eye Res. 5:283-293.

8. Napier, M. A., R. L. Vandlen, G. Albers-Schonberg, R. F. Nutt, S. Brady, T. Lyle, R. Winquist, E. P. Faison, L. A. Heinel, and E. H. Blaine. 1984. Specific membrane receptors for atrial natriuretic factor in renal and vascular tissues. Proc. Natl. Acad. Sci. USA. 81:59465950.

9. Leitman, D. C., J. W. Andresen, T. Kuno, Y. Kamisaki, J. K. Chang, and Ferid Murad. 1986. Identification of multiple binding sites for atrial natriuretic factor by affinity cross-linking in cultured endothelial cells. J. Biol. Chem. 261:11650-11655.

10. Devine, E., L. Artman, G. Budzik, E. Bush, and W. Holleman. 1986. Distribution and elimination of intravenously administered atrial natriuretic hormone (ANH) to normal and nephrectomized rats. Fed. Proc. 45:1738. (Abstr.)

11. Katsube, N., D. Schwartz, and P. Needleman. 1986. Atriopeptin turnover: quantitative relationship between in vivo changes in plasma levels and atrial content. J. Pharmacol. Exp. Ther. 239:474479.

12. Yandle, T. G., I. Crozier, E. A. Espiner, H. Ikram, and M. G. Nicholls. 1985. Production, plasma levels, and clearance of atrial natriuretic peptide in man. Hypertension (Dallas). 7:838 (Abstr.)

13. Yandle, T. G., A. M. Richards, M. G. Nicholls, R. Cuneo, E. A. Espiner, and J. H. Livesey. 1986. Metabolic clearance rate and plasma half life of alpha-human atrial natriuretic peptide in man. Life Sci. 38:1827-1833.

14. Murthy, K. K., G. Thibault, E. L. Schriffrin, R. Garcia, L. Chartier, J. Gutkowska, J. Genest, and M. Cantin. 1986. Disappearance of atrial natriuretic factor from circulation in the rat. Peptides (NY). 7:241-246.

15. Segre, G. V., H. D. Niall, R. T. Sauer, and J. T. Potts, Jr. 1977. Edman degradation of radioiodinated parathyroid hormone: application to sequence analysis and hormone metabolism in vivo. Biochemistry. 16:2417-2427.
16. Flynn, T. G., and P. L. Davies. 1985. The biochemistry and molecular biology of atrial natriuretic factor. Biochem. J. 232:313321.

17. Inagami, T., K. S. Misono, R. T. Grammer, H. Fukumi, M. Maki, I. Tanaka, J. C. McKenzie, R. Takayanagi, K. N. Pandey, and M. Parmentier. 1985. Biochemical studies of rat atrial natriuretic factor. Clin. Exp. Hypertens. Part-A Theory Pract. A7:851-866.

18. Winquist, R. J., E. P. Baskin, E. P. Faison, R. W. Babilon, and G. P. Vlasuk. 1987. The actions of atrial natriuretic factor on the vascular wall. Can. J. Physiol. Pharmacol. 65:1684-1689.

19. Murthy, K. K., G. Thibault, R. Garcia, J. Gutkowska, J. Genest, and M. Cantin. 1986. Degradation of atrial natriuretic factor in the rat. Biochem. J. 240:461-469.

20. Crozier, I. G., M. G. Nicholls, H. Ikram, E. A. Espiner, T. G. Yandle, and S. Jans. 1986. Atrial natriuretic peptide in humans: production and clearance by various tissues. Hypertension. 8:II11-III5.

21. Espiner, E. A., M. G. Nicholls, T. G. Yandle, T. G. Crozier, R. C. Cuneo, D. McCormick, and H. Ikram. 1986. J. Hypertension. 4:S85-S91.

22. White, F. J., R. J. Rodeheffer, A. S. Hollister, T. Imada, T. Inagami. 1987. Hepatic clearance of endogenous atrial natriuretic factor in human subjects. Clin. Res. 35:334a. (Abstr.)

23. Veress, A. T., C. K. Chong, and H. Sonnenberg. 1985. Inactivation of atrial natriuretic factor in blood. Can. J. Physiol. Pharmacol. 63:1615-1617.

24. Schiffrin, E. L., M. Deslongchamps, and G. Thibault. 1985. Receptors for atrial natriuretic factor in human platelets: characterization and effects of sodium. Hypertension. 7:838. (Abstr.)

25. Schiffrin, E. L., M. Deslongchamps, and G. Thibault. 1986. Platelet binding sites for atrial natriuretic factor in humans: characterization and effects of sodium intake. Hypertension. 8:II6-II 10.

26. Cole, B. R., D. Schwartz, P. T. Manning, N. C. Katsube, and P. Needleman. 1986. Atriopeptins: circulating volume regulatory hormones with potential therapeutic role in chronic renal failure. $J$. $\mathrm{Hy}$ pertension. 4:513-516.

27. Misono, K. S., R. T. Grammer, H. Fukumi, and T. Inagami. 1984. Rat atrial natriuretic factor: isolation, structure and biological activities of four major peptides. Biochem. Biophys. Res. Commun. 123:444-451.

28. Stephenson, S. L., and A. J. Kenny. 1987. The hydrolysis of $\alpha$-human natriuretic peptide by pig kidney microvillar membranes is initiated by endopeptidase-24.11. Biochem. J. 243:183-187. 